\title{
Proctite Infeciosa:
}

\section{Valorizar o Diagnóstico Diferencial}

\section{Infectious Proctitis: The Value of Differential Diagnosis}

Dalila Costa ${ }^{1}$, Ana Célia Caetano ${ }^{1}$, Carla Rolanda ${ }^{1}$, Raquel Gonçalves ${ }^{1}$

\section{RESUMO}

As manifestações gastrointestinais de infeções sexualmente transmissíveis podem não ser precocemente reconhecidas. Perante o aumento dos comportamentos sexuais de risco é imperativo o reconhecimento da proctite infeciosa na prática clínica. Os autores descrevem o caso clínico de um homem de 28 anos, homossexual, com infeção pelo vírus de imunodeficiência adquirida (com contagem de células CD4+ normal), que recorreu por múltiplas vezes ao serviço de urgência por quadro de retorragias e fezes com muco purulento, obstipação com tenesmo, aerocolia intensa e emagrecimento, sem melhoria com tratamento sintomático. A retosigmoidoscopia revelou uma proctite ulcerativa severa, com achados inespecíficos na histologia. A pesquisa de DNA do vírus Epstein-Barr e citomegalovírus em biópsia subsequente foi positiva, pelo que iniciou terapêutica dirigida, com melhoria paulatina do quadro clínico e endoscópico. Este caso realça a complexidade do diagnóstico da proctite infeciosa e alerta para a possível coexistência de múltiplos agentes transmitidos sexualmente.

PALAVRAS-CHAVE: Infeções por VIH; Infeções por Citomegalovírus; Infeções por Vírus Epstein-Barr; Proctite

\section{ABSTRACT}

Gastrointestinal manifestations of sexually transmitted infections may not be early recognized. Given the increased high-risk sexual behavior, the recognition of infectious proctitis in the daily practice is imperative. The authors present a 28-year-old male patient infected with human immunodeficiency virus (with normal CD4+ count), who was admitted for several times to the emergency room due to rectal bleeding, purulent discharge, constipation with tenesmus, intense aerocoly and weight loss, with no improvement with support therapy. Rectosigmoidoscopy revealed an intense ulcerative proctitis with non-specific inflammation in histopathological analysis. Cytomegalovirus and Epstein-Barr virus DNA were positive in the following biopsy and specific therapy was started with delayed symptom and endoscopic resolution. This case enhances the complexity of proctitis diagnose and rises awareness of multiple sexually transmitted co-infections.

KEYWORDS: Cytomegalovirus Infections; Epstein-Barr Virus Infections; HIV Infections; Proctitis 


\section{INTRODUÇÃO}

As manifestações gastrointestinais de infeções sexualmente transmissíveis (IST) são comuns, porém podem não ser precocemente reconhecidas. A proctite infeciosa resulta frequentemente de agentes adquiridos por esta via de transmissão. ${ }^{1}$ Caracteriza-se pela presença de tenesmo, retorragia, dor ou desconforto anorretal, urgência defecatória, obstipação, entre outros sintomas. A sintomatologia pode variar de acordo com o agente ou o processo patológico, mas pode mimetizar outras patologias inflamatórias, o que dificulta o diagnóstico. ${ }^{2}$

Atualmente observa-se um aumento dos comportamentos sexuais de risco em paralelo com a taxa de IST na Europa. ${ }^{3}$ Perante o ressurgimento deste problema de saúde pública, é imperativo o reconhecimento da proctite infeciosa na prática clínica. O caso clínico descrito reflete a dificuldade no diagnóstico e na orientação terapêutica desta entidade.

\section{CASO CLÍNICO}

Doente do sexo masculino, 28 anos de idade, raça negra, homossexual, com antecedentes de comportamentos sexuais de risco prévios e infeção pelo vírus de imunodeficiência adquirida (VIH) diagnosticada em 2011; infeção por Treponema pallidum no mesmo período, mas doente nega conhecimento de tratamento de síflis primária. Imune para o vírus Epstein-Barr (EBV), citomegalovírus (CMV), herpes simplex (HSV) $1 \mathrm{e} 2$.

Recorreu ao serviço de urgência (SU) no final de novembro de 2015 por retorragias com 1 semana de evolução, tendo-se observado uma fissura anal posterior e tido alta com terapêutica dirigida. Retornou múltiplas vezes ao SU com agravamento progressivo dos sintomas: manutenção de retorragias, fezes com muco purulento, tenesmo, dor abdominal tipo cólica, obstipação, aerocolia e emagrecimento de $10 \mathrm{~kg}$ em 2 meses, sem melhoria com venotrópico tópico, diltiazem, analgesia, anti-espasmódico e metronidazol. Negava vómitos, náuseas, anorexia, febre ou outro sintoma sistémico.

Perante este quadro clínico, uma carga viral de 105000 cópias/ml e contagem de células CD4+ de 582/ $\mathrm{mm}^{3}$, o doente iniciou terapêutica antirretroviral em janeiro de 2016. Foi encaminhado para a consulta de Gastrenterologia no final de janeiro para iniciar estudo complementar. Analiticamente apresentava hemoglobina de $11,4 \mathrm{~g} / \mathrm{dL}$ (valor habitual de 17,0 g/dL), normocítica e normocrómica; proteína C reativa de $93 \mathrm{mg} / \mathrm{L}$, sem outras alterações de relevo. Os exames microbiológico e parasitológico de fezes foram negativos (incluindo agentes oportunis-



FIGURA 1. A colonoscopia revela úlceras ovaladas de base branca intercaladas com mucosa normal no cólon sigmoide (esquerda) e mucosa ulcerada e friável de modo circunferencial e contínuo no reto (direita).

tas como Cryptosporidium, Microsporidium, Isospora e Mycobacterium sp), assim como o antigénio Clostridium difficile.

A tomografia computorizada abdominal mostrou densificação acentuada dos planos adiposos peri-retais e pequenas adenopatias. A endoscopia alta revelou candidíase esofágica. A colonoscopia mostrou úlceras ovaladas de base branca intercaladas com mucosa normal no cólon sigmoide e mucosa retal ulcerada e friável de modo circunferencial e contínuo (Fig. 1). A histologia revelou distorção arquitetural, diminuição do número de células caliciformes e abundante infiltrado inflamatório, com lesões de criptite e microabcessos sugestivo de colite ativa infeciosa. Perante o quadro clínico, iniciou-se empiricamente doxiciclina (100 mg, bid, 7 dias) e mesalazina oral e tópica.

Após 2 semanas de tratamento, o quadro clínico persistiu apesar de normalização da PCR e melhoria da hemoglobina. A retosigmoidoscopia (RSC) revelou discreta melhoria com manutenção da proctite ulcerativa contínua e circunferencial no reto distal; úlceras extensas intercaladas com mucosa congestiva no reto proximal mas ausência de lesões no cólon sigmoide. As biópsias retais apresentaram resultados sobreponíveis e presença de DNA do CMV e EBV, pelo que se iniciou terapêutica dirigida com valganciclovir $(900$ mg, bid, 3 semanas). O DNA de HSV, Chlamydia trachomatis e Neisseria gonorrhoeae foram negativos.

Por ausência de melhoria clínica após 3 semanas, o doente foi internado para efetuar terapêutica endovenosa com ganciclovir ( $5 \mathrm{mg} / \mathrm{kg}$, id, 3 semanas), e por suspeita (posteriormente excluída) de sobreinfeção bacteriana, iniciou ciprofloxacina (500 mg, bid, 7 dias) empiricamente. Durante o internamento, o doente apresentou uma melhoria intermitente da clínica, pelo que outras etiologias foram consideradas, nomeadamente sífilis secundária. Por apresentar teste não treponémico VDRL de 1/8 (valor anterior 1/2) e por se desconhecer terapêutica prévia, optou-se por efetuar a primeira dose de penicilina benzatínica (2 400000 U/semana, 3 semanas). 


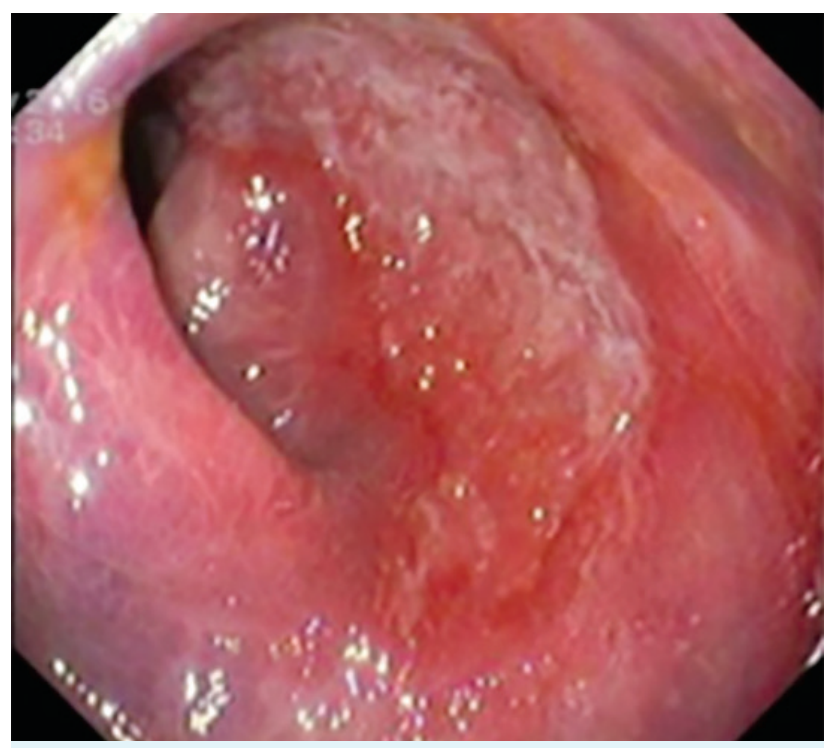

FIGURA 2. A retosigmoidoscopia de reavaliação mostra sinais de reepitelização das áreas de ulceração da mucosa retal.

À data da alta, após 3 semanas de internamento e 6 meses desde o início do quadro clínico, o doente referia melhoria franca da sintomatologia e apresentava PCR negativa e hemoglobina de 15,3 g/dL. A RSC de reavaliação revelou sinais de reepitelização das áreas de ulceração da mucosa retal (Fig. 2).

\section{DISCUSSÃO}

Os agentes patogénicos sexualmente transmitidos mais prevalentes na proctite infeciosa são a Neisseria gonorrhoeae, Clamydia trachomatis, HSV e o Treponema pallidum. ${ }^{4}$ A maioria das infeções são assintomáticas, ${ }^{2}$ mas em doentes com VIH, estas podem assumir uma maior gravidade. $^{5}$ Nesta população, a infeção por CMV ou outros agentes oportunistas devem também ser considerados, bem como agentes não transmitidos por via sexual como Mycobacterium sp, Cryptosporidium, Microsporidium e Isospora belli. ${ }^{5}$

A infeção por CMV é uma importante causa de morbilidade e mortalidade nos doentes com infeção por VIH e o trato gastrointestinal é o local primordialmente escoIhido. Geralmente, a incidência de infeção por CMV em doentes infetados com $\mathrm{VIH}$ relaciona-se com o número de células CD4+, sendo rara a descrição em doentes com uma contagem normal de células ${ }^{6,7}$ como acontece no caso descrito. No entanto, a presença de uma doença definidora de SIDA, como a candidíase esofágica neste doente, sugere um grau de imunossupressão superior ao sugerido pela contagem de linfócitos. A carga viral do VIH superior a 100000 cópias/mL é também um fator preditivo para doença pelo CMV. ${ }^{8}$

O diagnóstico da proctite por CMV é baseado na ulceração inespecífica da mucosa associada à presença das inclusões intranucleares do vírus no tecido biopsado. ${ }^{6} \mathrm{~A}$ baixa sensibilidade deste achado pode dificultar o diagnóstico e atrasar o início da terapêutica dirigida, como verificado neste caso. A identificação do DNA na mucosa ulcerada não permite diferenciar entre infeção ativa e latente, especialmente nos doentes infetados com VIH., 9,10 No entanto, perante o quadro clínico descrito, assumiu-se como diagnóstico mais provável. A resposta lenta à terapêutica dirigida pode ser explicada pela utilização inicial da via oral. Segundo as recomendações atuais, na colite moderada a severa está recomendada terapêutica de indução com ganciclovir endovenoso.?

$\mathrm{O}$ atingimento do trato gastrointestinal pelo vírus EBV é incomum. Geralmente associa-se a uma doença linfoproliferativa, apesar de raras referências a colite ulcerativa na literatura. ${ }^{11}$ A reativação concomitante do vírus CMV e EBV foi recentemente reportado num caso clínico de um doente imunodeprimido. Este apresentou-se com uma colite ulcerativa severa com características semelhantes a doença inflamatória intestinal, com resolução clínica após 2 ciclos prolongados de ganciclovir. ${ }^{12}$ À semelhança, no caso clínico descrito, a infeção concomitante destes dois herpesvírus pode também explicar a resolução paulatina do quadro clínico e endoscópico. Em adição, tal como acontece com a proctite por $\mathrm{HSV},{ }^{5}$ a infeção por VIH poderá potenciar a gravidade das lesões e o atraso da resposta à terapêutica instituída. O follow-up deste doente será importante para compreender o comportamento da proctite infeciosa por EBV, nomeadamente a possível evolução para doença linfoproliferativa.

A possibilidade de uma proctite sifílica também não pode ser excluída, perante os antecedentes do doente, a alteração do valor de VDRL e a incidência deste agente nesta população de risco.

Considerando o aumento dos comportamentos de risco sexuais na atualidade, este caso clínico realça a necessidade de reconhecer a proctite infeciosa na prática diária, destaca a complexidade do diagnóstico e alerta para a possível coexistência de múltiplos agentes transmitidos sexualmente, sobretudo nos doentes com infeção VIH, o que dificulta a orientação terapêutica.

CONFLITOS DE INTERESSE: Os autores declaram a inexistência de conflitos de interesse na realização do trabalho.

FONTES DE FINANCIAMENTO: Não existiram fontes externas de financiamento para a realização deste artigo.

CONFIDENCIALIDADE DOS DADOS: Os autores declaram ter seguido os protocolos do seu centro de trabalho acerca da publicação dos dados do doente. 


\section{REFERÊNCIAS}

1. Hamlyn E, Taylor C. Sexually transmitted proctitis. Postgrad Med J. 2006;82:733-6.

2. Vries H, Zingoni A, White J, Ross J, Kreuter A. 2013 European Guideline on the management of proctitis, proctocolitis and enteritis caused by sexually transmissible pathogens. Int J STD \& AIDS. 2013;25:465-474.

3. Fenton K. Recent trends in the epidemiology of sexually transmitted infections in the European Union. Sexy Transm Infect. 2004;80:255-263.

4. Klausner J, Kohn R, Kent C. Etiology of clinical proctitis among men who have sex with men. Clin Infect Dis. 2004;38:300-2.

5. Workowski K. Centers for Disease Control and Prevention Sexually Transmitted Diseases Treatment Guidelines. Clin Infect Dis. 2015;61(suppl 8):S759-S762.

6. Ross A, Novak Z, Pati S, Boppana S. Diagnosis of Cytomegalovirus Infections. Infect Disord Drug Targets. 2011:11:466-74.

7. Paparone PP, Paparone PA. Cytomegalovirus Colitis in a Human Immunodeficiency Virus-Positive Patient With a Normal CD4 Count. Am J Med Sci. 2012;344:508-510.
8. Salmon-Ceron D, Mazeron MC, Chaput S, Boukli N, Senechal B, Houhou N, et al. Plasmacytomegalovirus DNA, pp65 antigenaemia and a low CD4 cell count remain risk factors for cytomegalovirus disease in patients receiving highly active antiretroviral therapy. AIDS. 2000;14:1041-9.

9. Masur H, Brooks J, Benson C, Holmes K, Pau A, Kaplan J. Prevention and treatment of opportunistic infections in hiv-infected adults and adolescents: updated guidelines from the Centers for Disease Control and Prevention, National Institutes of Health, and HIV Medicine Association of the Infectious Diseases Society of America. Clin Infect Dis. 2014;58:1308-11.

10. Jahan M. Laboratory diagnosis of CMV infection: a review. Bangladesh J Med Microbiol. 2012;4.

11. Karlitz J, Li S, Holman R, Rice M. EBV-associated colitis mimicking IBD in an immunocompetent individual. Nat Rev Gastroentero Hepatol. 2010;8:50-54.

12. Matsumoto H, Kimura Y, Murao T, Osawa M, Akiyama T, Mannoji K, et al. Severe colitis associated with both epstein-barr virus and cytomegalovirus reactivation in a patient with severe aplastic anemia. Case Rep Gastroenterol. 2014;8:240-4. 